\title{
Diamond Membrane Production: The Critical Role of Radicals in the Non-Contact Electrochemical Etching of $\mathbf{s p}^{\mathbf{2}}$ Carbon
}

\author{
Joshua J. Tully ${ }^{1}$, Emily Braxton ${ }^{1,2}$, Samuel J. Cobb ${ }^{1,3,7}$, Ben G. Breeze ${ }^{4}$, Matthew Markham ${ }^{5}$, \\ Mark E.Newton ${ }^{4}$, Paramaconi Rodriguez ${ }^{6}$ and Julie V. Macpherson ${ }^{1 *}$ \\ ${ }^{1}$ Department of Chemistry, University of Warwick, Coventry, CV4 7AL, UK \\ ${ }^{2}$ Molecular Analytical Science Centre for Doctoral Training, University of Warwick, \\ Coventry, CV4 7AL, UK \\ ${ }^{3}$ EPSRC Centre for Doctoral Training in Diamond Science and Technology, University of \\ Warwick, Coventry, CV4 7AL, UK \\ ${ }^{4}$ Department of Physics, University of Warwick, Coventry, CV4 7AL, UK \\ ${ }^{5}$ Element Six Ltd, Global Innovation Centre, Fermi Ave, Didcot, OX11 0QR, UK \\ ${ }^{6}$ School of Chemistry, University of Birmingham, Birmingham, B15 2TT, UK \\ ${ }^{7}$ Yusuf Hamied Department of Chemistry, University of Cambridge, CB2 1EW, UK
}

Sub-micrometre single crystal diamond membranes are of huge importance for next generation optical, quantum and electronic device applications. Electrochemical etching has proven a critical step in the production of such membranes. Etching is used to selectively remove a very thin layer of sub-surface $\mathrm{sp}^{2}$ bonded carbon, prepared by ion implantation in bulk diamond, releasing the diamond membrane. Due to the nanosized dimensions, etching is carried out using non-contact electrochemistry in low conductivity solutions (bipolar arrangement) which whilst effective, results in extremely slow etch rates. In this work, a new method of non-contact electrochemical etching is presented which uses high conductivity, high concentration, fully dissociated aqueous electrolytes. Careful choice of the electrolyte anion results in significant improvements in the $\mathrm{sp}^{2}$ carbon etch rate. In particular, we show both chloride and sulfate electrolytes increase etch rates significantly (up to $\times 40$ for sulfate) compared to the current state-of-the-art. Electron paramagnetic resonance experiments, recorded after the electrode potential has been switched off, reveal sizeable hydroxyl radical concentrations at timescales $>10^{7}$ longer than their lifetime $(\leq \mu \mathrm{s})$. These measurements highlight the importance of electrochemically initiated, solution chemistry radical generation and regeneration pathways in high concentration sulfate and chloride solutions for nano-etching applications.

Keywords: Diamond Membranes, Electrochemical Etching, Carbon Etching, Sulfate Electrolytes, Radicals, Hydroxyl Radicals, EPR 


\section{Introduction}

Diamond is an exceptional material well known for its extreme properties of hardness, thermal conductivity and wide optical transmission, making it a material of significant interest in emerging technologies. ${ }^{1}$ To develop the next generation of optical, quantum and electronic devices, ${ }^{2-4}$ nanostructuring of the diamond is often required. In particular for quantum technology applications, high-quality single crystal diamond membranes of sub-micron thickness, containing negatively charged nitrogen vacancy defects are essential. ${ }^{2,5,6}$ While diamond membranes can be prepared using mechanical polishing, this is possible down to only ca. $10 \mu \mathrm{m}$ thickness. ${ }^{4}$ Such membranes are typically wedge-shaped due to the complexities of achieving co-planarity at this thickness over a large area $\left(\mathrm{mm}^{2}\right)$. Moreover, mechanical polishing can result in sub-surface damage, penetrating microns deep, which requires further processing steps to achieve the surface quality required for quantum applications. ${ }^{7-9}$

Ion implantation is used to damage a well-defined sub-surface region of the diamond, followed by high-temperature annealing to convert this damaged diamond to $\mathrm{sp}^{2}$ carbon. After the subsurface $\mathrm{sp}^{2}$ carbon layer has been prepared the membrane can be removed via etching of this layer, also known as "lift-off". This method has been proposed as an alternative to mechanical polishing for producing thin, uniform diamond membranes., ${ }^{40-13}$ Diamond membrane thickness is determined by the implantation energy and as the damage layer implants parallel to the top surface, the resulting membrane has a consistent thickness at all points. The lift off process is key to success of the diamond membrane nanofabrication process. Oxygen dry etching ${ }^{13}$ has been used, but was found to be slow ( $5 \mathrm{hrs}$ for separation of a $2 \mathrm{~mm}$ square membrane) with some damage to the membrane also observed due to etching of the diamond as well as the $\mathrm{sp}^{2}$ carbon layer. ${ }^{13}$

Electrochemical (EC) etching has also been proposed as an etch method, due to the advantages electrochemistry brings in terms of reduced cost of the set-up and negligible damage to the diamond. ${ }^{10}$ However, unlike traditional EC etching/electropolishing where direct contact is made to the conductive material and a potential applied to promote oxidative dissolution of the material itself, ${ }^{14,15}$ a non-contact EC set-up is required due to the nano-sized features of the embedded $\mathrm{sp}^{2}$ carbon. In order for the implanted $\mathrm{sp}^{2}$ carbon to experience a potential difference across the $\mathrm{sp}^{2}$ carbon, the use of low conductivity solutions was advocated; ${ }^{10,13}$ to drop a meaningful potential across the $\mathrm{sp}^{2}$ carbon/electrolyte interface, the resistance of the solution must be higher than that of the $\mathrm{sp}^{2}$ carbon layer. This concept is often referred to as bipolar 
electrochemistry. ${ }^{16,17}$ Unfortunately, using this approach, etch rates were found to be slower than reported for dry etching ${ }^{13}$, taking $10 \mathrm{hrs}$ to separate a $3 \times 3 \mathrm{~mm}$ membrane in a dilute chromic acid solution, even with an applied voltage of $100 \mathrm{~V} .{ }^{10}$ Thus, despite the importance of this process to the quantum optical communities, the EC etch process is still far from optimised for efficient $\mathrm{sp}^{2}$ carbon removal rates. ${ }^{4,13,18-21}$

In this paper we demonstrate a new non-contact EC nanofabrication method which can be used to etch conductive nanomaterials, where direct electrical contact to the conductive material is challenging. Rather than relying on a bipolar etch mechanism and low conductivity solutions, this method uses high conductivity, fully dissociated electrolytes in conjunction with electrochemical initiation of radical generating chemical pathways in solution. Etch rates of the graphitic layer are measured using in-situ optical microscopy. We explore how the choice of electrolyte and electrolyte concentration can significantly enhance $\mathrm{sp}^{2}$ carbon etch rates.

\section{Materials and Methods}

\subsection{Materials}

All solutions were prepared from ultrapure water (>18.2 $\mathrm{M} \Omega \mathrm{cm}$, Milli-Q, Millipore Corp.). Etch solutions comprised either $400 \mathrm{mM}$ boric acid $\left(\mathrm{H}_{3} \mathrm{BO}_{3}, 99.97 \%\right.$, Sigma Aldrich, UK) or $250 \mathrm{mM}$ salts in ultrapure water. Salts investigated included potassium nitrate $\left(\mathrm{KNO}_{3}, 99.97 \%\right.$, Sigma Aldrich, UK), potassium chloride ( $\mathrm{KCl}, \geq 99 \%$, Sigma Aldrich, UK), and potassium sulfate $\left(\mathrm{K}_{2} \mathrm{SO}_{4}\right.$, Pure, Acros Organics, US). Sulfuric acid $\left(\mathrm{H}_{2} \mathrm{SO}_{4},>96 \%\right.$, Merck, UK) was used at $0.3 \% v / v(50 \mathrm{mM})$ in ultrapure water. Mixed $\mathrm{K}_{2} \mathrm{SO}_{4} / \mathrm{H}_{2} \mathrm{SO}_{4}$ solutions were made to $250 \mathrm{mM}$ total sulfate concentrations in ultrapure water. Solutions for electron paramagnetic resonance (EPR) spectroscopy comprised of $250 \mathrm{mM} \mathrm{KNO}_{3}, \mathrm{KCl}$, and potassium sulfate $\left(\mathrm{K}_{2} \mathrm{SO}_{4}\right.$, Analysis Grade, Sigma Aldrich, UK) or $400 \mathrm{mM}$ boric acid salt in ultrapure water. The solution used for headspace on-line electrochemical mass spectrometry (HS-OLEMS) was $0.3 \% v / v$ (50 $\mathrm{mM})$ sulfuric acid $\left(\mathrm{H}_{2} \mathrm{SO}_{4}, 96 \%\right.$ Ultrapur, Merck, UK).

\subsection{Diamond Sample Preparation}

Optical grade chemical vapour deposition (CVD) and standard grade high pressure high temperature (HPHT, type 1b) single crystal diamond plates (Element Six Ltd., Harwell, UK) which are $\sim 500 \mu \mathrm{m}$ thick, and either $3.5 \mathrm{~mm}(3.5 \times 3.5 \mathrm{~mm}), 4.1 \mathrm{~mm}(4.1 \times 4.1 \mathrm{~mm})$ or 4.2 $\mathrm{mm}(4.2 \times 4.2 \mathrm{~mm})$ in size were used as the substrates for all studies, unless otherwise stated. The front face of each sample was mechanically polished to $\sim \mathrm{nm}$ roughness, and the rear face lapped to $\sim \mu \mathrm{m}$ roughness. Before ion implantation, samples were acid cleaned in concentrated 
$\mathrm{H}_{2} \mathrm{SO}_{4}\left(>96 \%\right.$, Merck, UK) saturated with $\mathrm{KNO}_{3}$ and heated at $200{ }^{\circ} \mathrm{C}$ for 30 minutes. This was followed by another 30 minutes in $200{ }^{\circ} \mathrm{C}_{2} \mathrm{SO}_{4}$ before rinsing in ultrapure water. ${ }^{22}$ After acid cleaning the implantation surface was cleaned in an oxygen/argon plasma (Emitech, K1050X Plasma Asher, $80 \mathrm{~W}, 60 \mathrm{~s}$ ). The polished face was then implanted (Ion Beam Centre, University of Surrey, UK) with $2 \times 10^{16}$ carbon atoms (at $2 \mathrm{MeV}$ ) per square centimetre, to produce a damage layer $400 \mathrm{~nm}$ below the surface, and approximately $1000 \mathrm{~nm}$ thick, as calculated by stopping range of ions in matter (SRIM) simulations (SI.1). ${ }^{23}$ The implanted samples were annealed at $1300{ }^{\circ} \mathrm{C}$ for $2 \mathrm{hrs}$, to convert the damaged region into sp $\mathrm{s}^{2}$ carbon. ${ }^{24}$

After annealing the samples were then acid cleaned using the method described above and then characterised by Raman spectroscopy to verify that a sub-surface $\mathrm{sp}^{2}$ carbon layer was present (SI.2). Given the thickness of the $\mathrm{sp}^{2}$ carbon layer is known from simulations, $\mathrm{sp}^{2}$ carbon volumes for each substrate can be determined as $0.0123 \mathrm{~mm}^{3}$ for $3.5 \mathrm{~mm}$ samples, $0.0168 \mathrm{~mm}^{3}$ for $4.1 \mathrm{~mm}$ and $0.0175 \mathrm{~mm}^{3}$ for $4.2 \mathrm{~mm}$. A full tabulation of experiments and samples can be found in SI.3. Note, due to the limited availability of the samples used, it was necessary to complete some work without repeats.

\subsection{Electrochemical Etching}

Etching of single crystal diamond substrates took place in a custom designed 3D printed (Taz 6, Lulzbot, USA) polyethylene terephthalate cell. The electrodes used were two Pt wire electrodes $(0.75 \mathrm{~mm}$ in diameter and $2 \mathrm{~cm}$ in length) spaced $6 \mathrm{~mm}$ apart, as shown in Figure 1. A variable DC power supply (EA-PS 9750-04, Elektro-Automatik GmbH, Germany) was employed to apply a potential between the two electrodes, operating in a potential limiting mode at $30 \mathrm{~V}$ (approximately $+15 \mathrm{~V}$ and $-15 \mathrm{~V}$ versus ground), with a current value dependent on the solution composition. The diamond substrate, with embedded $\mathrm{sp}^{2}$ carbon layer was bonded (lapped face on) to a polycarbonate (RS Components, UK) support using a low-bloom cyanoacrylate adhesive (Loktite 460, Henkel, Germany), making sure no adhesive was visible to solution. This piece of polycarbonate was then placed into a slot, for centring purposes, with the polycarbonate face on which the diamond is adhered, held against the Pt electrodes (Figure 1). This ensures that the diamond plate was orientated such that the square face was perpendicular to the base of the etch cell, aligning the $\mathrm{sp}^{2}$ carbon layer in plane with the Pt wire 
electrodes. The cell was designed with a light path for transmission imaging of samples undergoing etching (Figure 1).

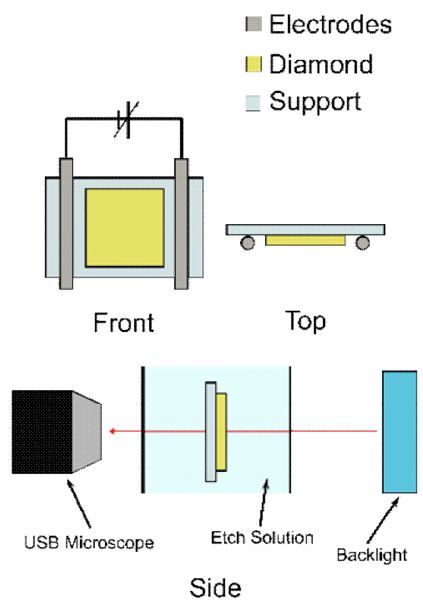

Figure 1: Schematic of the etch cell showing the arrangement of sample (yellow), electrodes (grey), and polycarbonate support (light blue) with front (as seen by the USB microscope), top and side (electrodes omitted for clarity) views displayed.

A digital USB microscope (VMS-001, ×20-90 magnification, Veho, UK) was used to capture time lapse images of etch progress. To maintain constant solution composition and temperature, a flow system was also employed with a temperature-controlled reservoir operating in the range of $10-70{ }^{\circ} \mathrm{C}$. Unless otherwise stated etches were performed at $25{ }^{\circ} \mathrm{C}$. A photograph of the etch set-up can be found in SI.4. Etch solution was circulated from this reservoir into the cell and returned via an outflow at a flow rate of $200 \mathrm{ml} \mathrm{min}$. The inlet was intentionally placed away from the electrodes to minimise flow effects. Although flow will increase mass-transport to and from the electrodes it is likely the production of gas bubbles from water electrolysis at the Pt electrodes will be a much more significant contributor to increased mass-transport.

\subsection{Image Analysis}

A MATLAB (Version 2017b, MathWorks) script was used to analyse all time-lapse data of the etch processes. Each frame from the video capture was extracted. The region of interest (i.e. the diamond substrate) is defined on the first image and the script used to calculate what proportion of that area corresponds to the etched region; these match RGB values provided in the script. This proportion is then converted to an area and then a volume, using the thickness of $\mathrm{sp}^{2}$ carbon of ca. $1000 \mathrm{~nm}$ as calculated from SRIM simulations, SI.1. The volume etched is then plotted versus etch time to create an etch profile. 


\subsection{Electron Paramagnetic Resonance Spectroscopy}

For EPR measurements, electrolysis of solutions containing either $250 \mathrm{mM} \mathrm{K}_{2} \mathrm{SO}_{4}, 250 \mathrm{mM}$ $\mathrm{KCl}, 250 \mathrm{mM} \mathrm{KNO}_{3}$ or $\sim 400 \mathrm{mM} \mathrm{H}_{3} \mathrm{BO}_{3}$ was performed with no recirculating flow, in a single compartment cell. $30 \mathrm{~V}$ was applied between the two platinum electrodes of the same geometry as those used in the etch cell in the solution of interest. After an electrolysis time of 15 minutes the potential was switched off and approximately $10 \mathrm{mM}$ of the spin trap 5,5-dimethyl-1pyrroline-N-oxide (DMPO; Enzo Life Sciences, USA) was added to the solution and mixed thoroughly. The time period from switching off the potential to adding the spin trap was ca. 30 s. From the resultant solution, an aliquot of the electrolysis mixture was sampled and the EPR spectrum recorded. The EPR signals for the DMPO spin adducts were recorded on an X-band spectrometer (EMX, Bruker, Germany) fitted with a HS cylindrical resonator (4119HS/0207, Bruker, Germany). Measurements were performed in a quartz EPR tube with a $1 \mathrm{~mm}$ inner diameter (Wilmad® quartz (CFQ) EPR tubes, Sigma-Aldrich, UK). For all measurements the following spectrometer parameters were used: a non-saturating microwave power of $20 \mathrm{~mW}$; central magnetic field, $352 \mathrm{mT}$; scan width, $10 \mathrm{mT}$ and a modulation amplitude, $0.05 \mathrm{mT}$. All spectra reported are an average of 9 scans. Fitting and simulation of the EPR spectra was performed using the MATLAB package EasySpin (Version 5.2.25). ${ }^{25}$

\section{Results and Discussion}

\subsection{Measuring the material etch rate}

The etch rate, as a function of solution composition, of the ca. $1000 \mathrm{~nm}$ (SI.1) thick sp ${ }^{2}$ carbon layer embedded in the freestanding single crystal diamond substrates, was monitored optically, in transmission mode, using a USB microscope (Figure 1). An exemplar optical image of the time-dependent removal of the $\mathrm{sp}^{2}$ carbon layer is shown in Figure 2, here recorded over a period of $2 \mathrm{hrs}$ in $250 \mathrm{mM} \mathrm{K} \mathrm{SO}_{4}$. Images were recorded every $10 \mathrm{~s}$ from application of the potential. At time, $t=0$ mins, the image appears black, due the presence of a complete $\mathrm{sp}^{2}$ carbon layer. EC etching of this layer is monitored via the colour change of the sample from black to colourless, the latter representing the translucent diamond as the $\mathrm{sp}^{2}$ carbon layer is removed. This colour change was used to quantify the area (and volume, from knowledge of implant thickness) of $\mathrm{sp}^{2}$ carbon removed as a function of etch time. The heterogeneous nature of the etch process, as shown by Figure 2, is typical of all etches in the different solutions observed under these flow conditions, the only difference being the timescale of the removal process. In most cases, etching begins at two edges of the $\mathrm{sp}^{2}$ carbon layer and then proceeds 
inwards. The locations at which etching commenced for each different experiment are tabulated in SI.3.

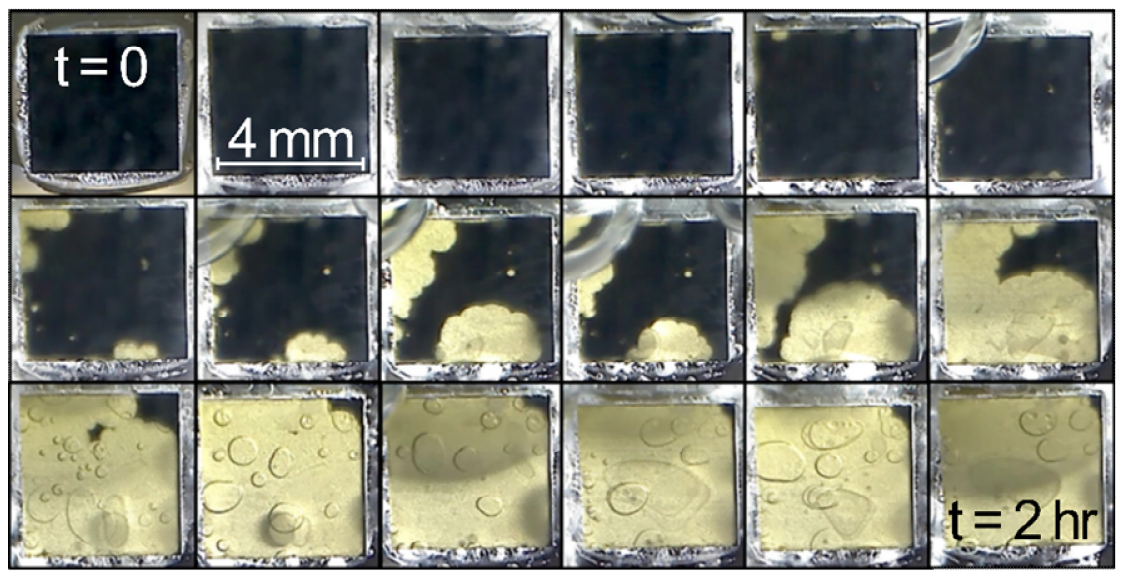

Figure 2: Optical image capture of the etch progress on a $4.2 \mathrm{~mm} \times 4.2 \mathrm{~mm}$ HPHT diamond in aerated $250 \mathrm{mM}$ $\mathrm{K}_{2} \mathrm{SO}_{4}$ solution with $30 \mathrm{~V}$ applied between two Pt electrodes, from $t=0$ to $t=2 \mathrm{hrs}$. Each image is separated by approximately 8 minutes of etching in in $250 \mathrm{mM} \mathrm{K}_{2} \mathrm{SO}_{4}$. Anode and cathode positioned to the left and right of the frame (out of view), respectively.

All etches in all solutions examined ( $n=27$ in total) had a sigmoidal shape, as shown in the exemplar etch rate data (etch volume vs time) in Figure 3, for a $250 \mathrm{mM} \mathrm{K}_{2} \mathrm{SO}_{4}$ solution. All data was fitted with a sigmoid (black line, Figure 3) and this fit used to provide insight into the etch characteristics. The curve could be divided into four distinct sections. First, the induction period, (yellow shaded area) second, the bulk etch region where the rate of etching is highest and linear and where the majority of material removal occurs (pink shaded area). Third, the bulk etching limit, where the limited amount of material remaining leads to a decrease in rate (blue shaded area), before finally reaching the final region, the etching complete region (grey shaded area) and no $\mathrm{sp}^{2}$ carbon remains. 


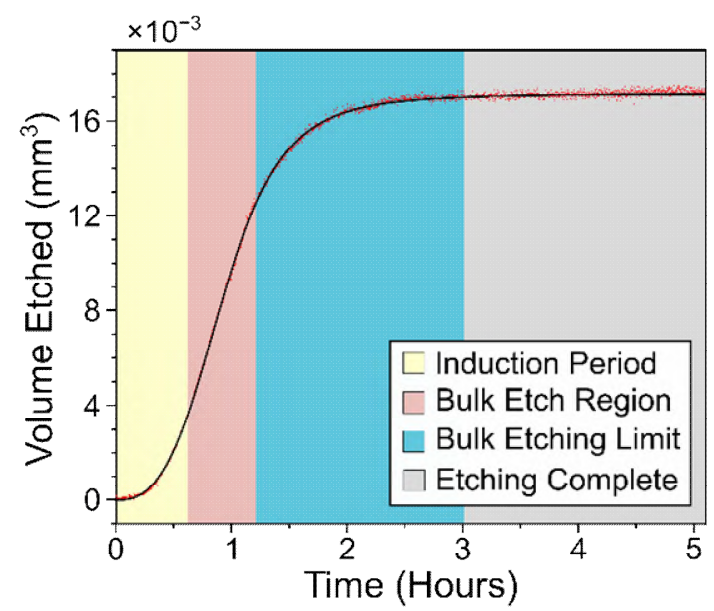

Figure 3: Exemplar etch profile from in-situ transmission microscope imaging. The raw data points $(n=6500$, red) are fitted with a sigmoidal function (black) and three distinct regions are defined. Etching is considered complete at $3 \mathrm{hrs}$ as no visible remnants of the $\mathrm{sp}^{2}$ carbon layer remains. Conditions: $4.1 \mathrm{~mm} \times 4.1 \mathrm{~mm} \mathrm{CVD}$ sample in aerated $250 \mathrm{mM}$ solution of $\mathrm{K}_{2} \mathrm{SO}_{4}$ with $30 \mathrm{~V}$ applied between the electrodes at $25^{\circ} \mathrm{C}$.

The induction period, during which very little etching takes place, varied in length for the range of conditions tested, however faster bulk etch rates typically resulted in shorter induction periods. We speculate that the existence of an induction period is as a result of either the $\mathrm{sp}^{2}$ carbon region not extending completely to the edge of the diamond, or a structurally different form of $\mathrm{sp}^{2}$ carbon at the edge versus the interior. In the majority of etches, etching began from two to three randomly distributed individual sites around the plate.

To assess the impact of solution conditions and composition on the etch rate, we focused on the bulk etch region (pink), which is where the majority of material is removed. In the bulk etching limit (blue area), as with the induction period (yellow area), we believe the material properties of the $\mathrm{sp}^{2}$ carbon implanted diamond play a more significant role in controlling the etch characteristics. This will form the subject of further work. Bulk etch rates were thus used as the quantitative metric for comparing the efficacy of different electrolyte solutions. Volumetric etch rates (in $\mathrm{mm}^{3} \mathrm{hr}^{-1}$ ) were determined by analysing the gradient over the region where $20 \%-70 \%$ of the total volume of $\mathrm{sp}^{2}$ carbon had been removed (i.e. $3.5 \mathrm{~mm}^{3}$ to 12.25 $\mathrm{mm}^{3}$ in Figure 3). This threshold was chosen as in all etches conducted it was within the pseudo-linear region of the sigmodal fit. Volume, rather than area, was also employed as a metric to acknowledge that the $\mathrm{sp}^{2}$ carbon layer is three-dimensional.

\subsection{Electrochemical Etching in Low Conductivity Solutions and Chemical Etching}

For these EC etch studies, half-saturated aerated $\mathrm{H}_{3} \mathrm{BO}_{3}(\sim 400 \mathrm{mM})$ was employed as the etch electrolyte, following literature precedent, ${ }^{4}$ in order to define a baseline etch rate under "bipolar" etch conditions. It is important to appreciate that whilst the concentration of $\mathrm{H}_{3} \mathrm{BO}_{3}$ 
is high, solution conductivity is very low (only $40 \mu \mathrm{S} \mathrm{cm}^{-1}$ which equates to a conductance of $\sim 3 \mu \mathrm{S}$ based on cell geometry) due to $\mathrm{H}_{3} \mathrm{BO}_{3}$ being a weak acid $\left(\mathrm{p} K_{\mathrm{a}}=9.2\right)$ and only partially deprotonated (dissociated). ${ }^{26}$ The conductivity of bulk amorphous $\mathrm{sp}^{2}$ carbon is $\sim 12.5 \mathrm{~S} \mathrm{~cm}^{-1}$, which based on layer dimensions represents a conductance of $\sim 1.3 \mathrm{mS} .{ }^{27}$ As such, the $\mathrm{sp}^{2}$ carbon layer is almost three orders of magnitude more conductive than the solution, and the majority of the potential between the two Pt wire electrodes will be dropped across the solution. Consequently, a large potential will be present at the $\mathrm{sp}^{2}$ carbon-electrolyte interface, which is capable of driving electron transfer reactions directly at this electrode surface. EC etching in this media gave an etch rate of $0.7 \times 10^{-3} \mathrm{~mm}^{3} \mathrm{hr}^{-1}$ (for a $4.2 \mathrm{~mm} \times 4.2 \mathrm{~mm}$ substrate), taking 20 hours for complete separation once the induction period had passed.

Under bipolar conditions, etching most likely occurs via direct electrochemical oxidative (Equations 1 and 2) and/or reductive (Equation 3) dissolution of the $\mathrm{sp}^{2}$ carbon. Note that the potentials given are thermodynamic potentials, with the experimentally observed potentials often being higher due to kinetic limitations. ${ }^{28,29}$

Equation 1: $\quad C_{(s)}+2 \mathrm{H}_{2} \mathrm{O}_{(a q)} \rightarrow \mathrm{CO}_{2(g)}+2 \mathrm{H}_{(a q)}^{+}+2 e^{-} \quad\left(E^{0}=0.518 \mathrm{~V} \text { vs RHE }\right)^{30}$ Equation 2: $\quad C_{(s)}+2 \mathrm{H}_{2} \mathrm{O}_{(a q)} \rightarrow \mathrm{CO}_{2(g)}+4 H_{(a q)}^{+}+4 e^{-} \quad\left(E^{0}=0.207 \mathrm{~V} \text { vs } \mathrm{RHE}\right)^{30}$ Equation 3: $\quad C_{(s)}+4 H_{(a q)}^{+}+4 e^{-} \rightarrow \mathrm{CH}_{4(g)} \quad\left(E^{0}=-0.132 \mathrm{~V} \text { vs RHE }\right)^{30}$ It is also possible electrochemically generated species which are highly oxidising in nature e.g. radicals, can cause etching of the $\mathrm{sp}^{2}$ carbon. For example, at high enough potentials, water can be oxidised to form hydroxyl radicals, $\mathrm{HO}_{(\mathrm{aq})}$, in solution (Equation 4$) .^{31}$

$$
\text { Equation 4: } \quad \mathrm{H}_{2} \mathrm{O}_{(l)} \rightarrow \mathrm{HO}_{(a q)}^{\cdot}+e^{-}+\frac{1}{2} \mathrm{H}_{2} \quad\left(E^{0}=2.7 \mathrm{~V} \text { vs RHE }\right)^{31}
$$

However, other pathways for water oxidation are more energetically favourable meaning it is only on surfaces where traditional water oxidation routes are strongly retarded, such as boron doped diamond that direct $\mathrm{HO}_{(\mathrm{aq})}$ production is significant. ${ }^{32} \mathrm{EC}$ radical generation via oxidation of the electrolyte is also unlikely as oxidation of borate anions / boric acid is not thought to result in radicals. This is also confirmed by the data in SI.5, which shows no EPR evidence of radical formation in the half-saturated aerated $\mathrm{H}_{3} \mathrm{BO}_{3}$ solution.

Cathodically, on $\mathrm{sp}^{2}$ carbon, the oxygen reduction reaction (ORR) favours a 2-electron pathway which results in production of the oxidising agent hydrogen peroxide, $\mathrm{H}_{2} \mathrm{O}_{2}$ (Equation 5). ${ }^{33}$ Dissolved oxygen will always be present due to the use of aerated solutions and the high 
potential difference applied across the two Pt electrodes; at the Pt anode, oxygen will be evolved from water oxidation.

$$
\text { Equation } 5: \quad O_{2}(g)+2 H^{+}{ }_{(a q)}+2 e^{-} \rightarrow H_{2} O_{2}(a q) \quad\left(E^{0}=1.8 \mathrm{~V} \text { vs RHE }\right)^{34}
$$

Note, we find that immersing a $\mathrm{sp}^{2}$ carbon implanted diamond sample into very high concentrations of $\mathrm{H}_{2} \mathrm{O}_{2}(30 \mathrm{wt} \%)$, much higher than those generated during ORR, at $25{ }^{\circ} \mathrm{C}$ for 24 hrs, with no applied potential, results in no visible etching of the $\mathrm{sp}^{2}$ carbon layer. This result suggested etching is either extremely slow or not possible using $\mathrm{H}_{2} \mathrm{O}_{2}$ alone.

\subsection{Electrochemical Etching in High Conductivity Solutions}

For the strong electrolyte (high solution conductivity) experiments three different electrolytes were employed, $\mathrm{KNO}_{3}, \mathrm{KCl}$, and $\mathrm{K}_{2} \mathrm{SO}_{4}$. The anion concentration was fixed at $250 \mathrm{mM}$, with solution conductivities almost three orders of magnitude higher than that for $\mathrm{H}_{3} \mathrm{BO}_{3}$; at $24 \mathrm{mS}$ $\mathrm{cm}^{-1}$ (conductance $\sim 1.8 \mathrm{mS}$ ), $28 \mathrm{mS} \mathrm{cm}^{-1}\left(\sim 2.1 \mathrm{mS}\right.$ ) and $42 \mathrm{mS} \mathrm{cm}^{-1}(\sim 3.2 \mathrm{mS})$ respectively. Note, with this increase in solution conductivity, bipolar contributions towards etching are expected to be significantly reduced due to considerably decreasing the potential drop between the $\mathrm{sp}^{2}$ carbon layer and electrolyte. Figure 4a,b shows the (a) etch profiles and (b) etch rates for the $\mathrm{sp}^{2}$ carbon implanted diamond substrate, in the bulk etch regions in the three different electrolytes. $\mathrm{H}_{3} \mathrm{BO}_{3}$ is included for comparison in the data in (b).
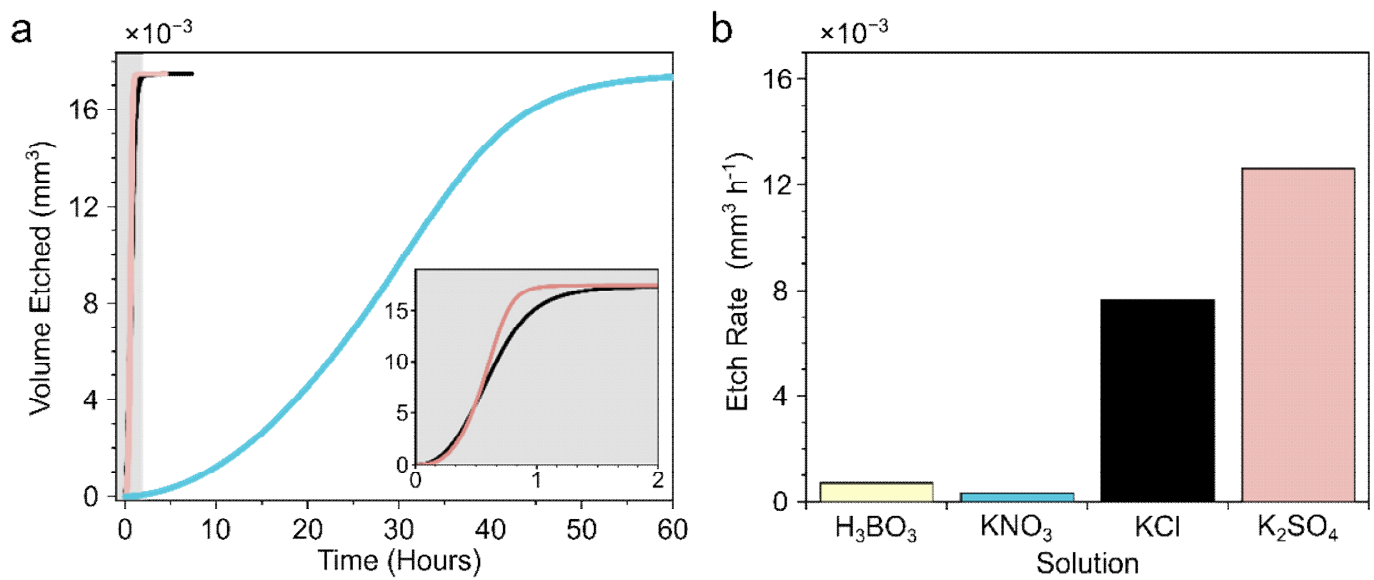

Figure 4 a) Etch profiles for etching of $4.2 \mathrm{~mm} \times 4.2 \mathrm{~mm}$ HPHT single crystal diamonds in aerated $250 \mathrm{mM}$ solutions of $\mathrm{KNO}_{3}$ (blue), $\mathrm{KCl}$ (black) and $\mathrm{K}_{2} \mathrm{SO}_{4}$ (pink). Inset, etch profile for $\mathrm{KCl}$ and $\mathrm{K}_{2} \mathrm{SO}_{4}$ from 0-2 hrs, the inset has the same units as the larger plot. $30 \mathrm{~V}$ was applied between the two Pt electrodes until etching was complete. Data was collected as $n=1$. b) Comparison of the bulk etch rates for each different electrolyte, plus aerated $400 \mathrm{mM} \mathrm{H}_{3} \mathrm{BO}_{3}$.

Whilst the etch rate in $\mathrm{KNO}_{3}$ was slower $\left(0.3 \times 10^{-3} \mathrm{~mm}^{3} \mathrm{hr}^{-1}\right)$ than that obtained using the $\mathrm{H}_{3} \mathrm{BO}_{3}$ both $\mathrm{KCl}\left(8 \times 10^{-3} \mathrm{~mm}^{3} \mathrm{hr}^{-1}\right)$ and $\mathrm{K}_{2} \mathrm{SO}_{4}\left(13 \times 10^{-3} \mathrm{~mm}^{3} \mathrm{hr}^{-1}\right)$ resulted in dramatic 
improvements in etch rate. Sulfate increased the bulk etch rate compared to both nitrate and boric acid by over an order of magnitude.

\subsection{Electron Paramagnetic Resonance Studies}

To explore the origin of these observations in more detail, EPR spectroscopy was employed to identify radicals produced during electrolysis. A cell with Pt electrodes identical to those used for etching, but with no diamond substrate present, was employed for the EPR measurements with $250 \mathrm{mM} \mathrm{KNO}_{3}, \mathrm{KCl}$ and $\mathrm{K}_{2} \mathrm{SO}_{4}$, undergoing electrolysis at $30 \mathrm{~V}$ for 15 minutes. In our non contact high conductivity experiments, the etchant is expected to be generated primarily at the non contact electrodes, via EC means, and must move through solution to the $\mathrm{sp}^{2}$ carbon. Hence, to be effective any radicals produced must either have a sufficiently long lifetime or, as most radicals in aqueous solution are notoriously short-lived e.g. $\leq \mu$ s timescale, are continually generated or regenerated through chemical reactions in solution. To show whether radicals were present at timescales significantly longer than their characteristic lifetimes, the DMPO spin trap was added after electrolysis had completed and the potential had been switched off; a process taking typically $30 \mathrm{~s}$. This contrast with the vast majority of EC-EPR experiments where the spin trap is added before starting electrolysis. ${ }^{35}$ DMPO was mixed into the solution and an aliquot taken for analysis in the EPR spectrometer, data shown in Figure 5. Note, the experiment was performed under stationary conditions which resulted in notable solution heating $\left(\sim 90{ }^{\circ} \mathrm{C}\right)$ compared to the flow experiments.

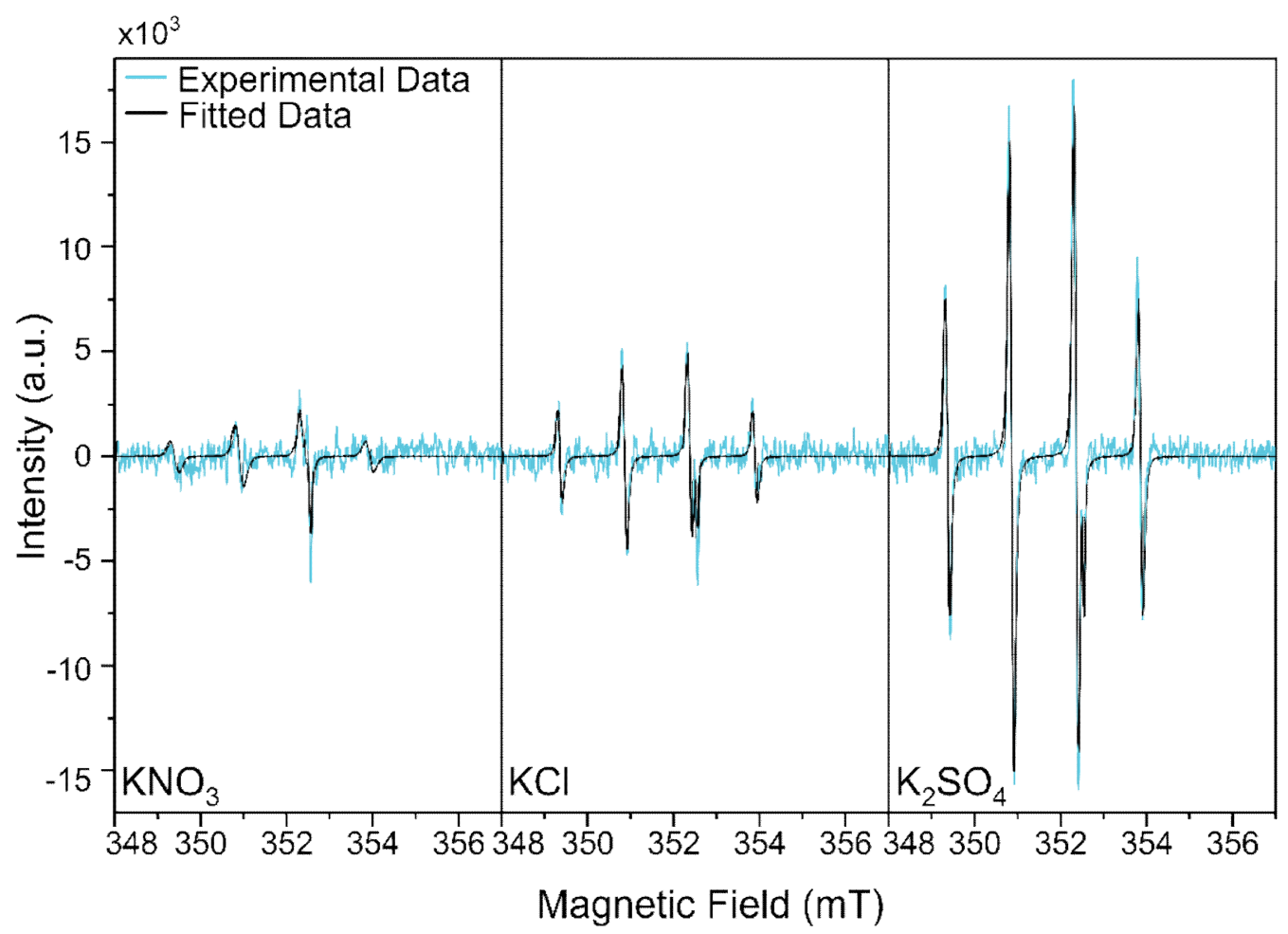


Figure 5: EPR spectra after 15 minutes of applied $30 \mathrm{~V}$ in $250 \mathrm{mM}$ solutions of aerated $\mathrm{KNO}_{3}, \mathrm{KCl}_{\text {and }} \mathrm{K}_{2} \mathrm{SO}_{4}$ (blue), as well as simulated spectra for the DMPO-OH spin adduct and D' quartz signal (black). Experimental Conditions: A non-saturating microwave power of $20 \mathrm{~mW}$; central magnetic field, $352 \mathrm{mT}$; scan width, $10 \mathrm{mT}$ and a modulation amplitude, $0.05 \mathrm{mT}$. All spectra reported are an average of 9 scans.

In all solutions, a clear signature for the DMPO-OH spin adduct is seen in the EPR spectrum, as well as a D' signature at $352 \mathrm{mT}$ from the quartz tube (included in the fit). ${ }^{36}$ The hyperfine coupling (A) extracted from the fitted data gave values of $A_{N}=1.50 \pm 0.01 \mathrm{mT} A_{H}=1.50 \pm 0.01$ $\mathrm{mT}$ which is in agreement with those expected for DMPO-OH. ${ }^{35}$ The DMPO-OH signature, which is indicative of radical concentration, varies in intensity in the order $\mathrm{NO}_{3}{ }^{-}$(low) $<\mathrm{Cl}^{-}<$ $\mathrm{SO}_{4}{ }^{2-}$ (high). Formation of $\mathrm{HO}_{(\mathrm{aq})}$ via the water oxidation route (Equation 4) is unlikely to be significant on $\mathrm{Pt}$, as discussed in section 3.2, this is due to the strong adsorption of $\mathrm{HO}^{\circ}$ on $\mathrm{Pt}$ electrodes leading to the formation of Pt oxide. ${ }^{37}$ Given the extremely high reactivity of $\mathrm{HO}^{\circ}$, its short lifetime $(\leq \mu \mathrm{s})^{38}$ and the fact that the spin trap is added after the potential has been switched off, observation of a DMPO-OH signal means that chemical routes in solution (initiated electrochemically) must be acting to generate or regenerate the $\mathrm{HO}^{\bullet}$ radical (discussed below).

On Pt surfaces, any $\mathrm{H}_{2} \mathrm{O}_{2}$ present can decompose to produce $\mathrm{HO}^{\bullet}$ via the Weiss mechanism (Equation 6). ${ }^{39}$

Equation 6: $\quad P t_{(s)}+\mathrm{H}_{2} \mathrm{O}_{2(\mathrm{aq})} \rightarrow P t_{(s)}^{*}+\mathrm{OH}_{(a q)}^{-}+\mathrm{HO}_{(a q)}^{\cdot}$

Whilst ORR on Pt is typically thought to predominantly occur via a 4-electron transfer pathway to form $\mathrm{H}_{2} \mathrm{O},{ }^{40}$ the amount of $\mathrm{H}_{2} \mathrm{O}_{2}$ produced on $\mathrm{Pt}$ via the 2-electron transfer pathway (Equation 5) has been shown to be dependent on solution composition. ${ }^{41-43}$ Once formed, HO• radicals will also recombine with themselves to form $\mathrm{H}_{2} \mathrm{O}_{2}$ (Equation 7) or react with $\mathrm{H}_{2} \mathrm{O}_{2}$ (Equation 8) to form the hydroperoxyl radical $\left(\mathrm{HO}_{2}{ }^{\circ}\right)$. Although $\mathrm{HO}_{2}{ }^{*}$ is lower in oxidising ability than $\mathrm{HO}^{*}$, thermodynamically it is capable of direct oxidation of the $\mathrm{sp}^{2}$ carbon layer. ${ }^{31}$

Equation 7:

$$
\mathrm{HO}_{(a q)}^{\bullet}+\mathrm{HO}_{(a q)}^{\cdot} \rightarrow \mathrm{H}_{2} \mathrm{O}_{2(a q)}
$$

Equation 8:

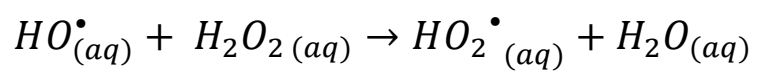

As $\mathrm{HO}_{2}{ }^{\circ}$ is a much longer lived radical in solution $(10 \mathrm{~s}-100 \mathrm{~s})^{44}$ compared to $\mathrm{HO}^{\bullet}$, if there is any $\mathrm{HO}_{2}{ }^{\bullet}$ present when the electrode potential is switched off and DMPO is added to solution, $\mathrm{HO}_{2}{ }^{\circ}$ will react with DMPO to form DMPO-OOH. However, DMPO-OOH is not stable (lifetime $\sim 1 \mathrm{~min}$ ) and will decay to give the much more stable spin adduct DMPO-OH $;{ }^{45-47}$ a 
process which will be even quicker in the elevated solution temperature of this EPR experiment. ${ }^{48}$ Since it takes a few minutes to transfer the sample into the EPR and tune the spectrometer, any DMPO-OOH present will have likely decayed to DMPO-OH.

Considering individual electrolytes, in $\mathrm{KNO}_{3}$, very small amounts of DMPO-OH are observed in the EPR spectra, suggesting a low concentration of radicals are produced, via either Equation 6 and/or Equation 8. In KCl, EPR measurements reveal over twice the amount of DMPO-OH compared with $\mathrm{KNO}_{3}$. Chloride ions have been shown to adsorb onto Pt surfaces and promote the generation of $\mathrm{H}_{2} \mathrm{O}_{2}$ via the 2-electron ORR route. ${ }^{41-43}$ To verify an increased concentration of $\mathrm{H}_{2} \mathrm{O}_{2}$ in the chloride electrolyte, UV-Vis spectroscopy experiments were recorded on the electrolysis solution every minute over a six minute period (SI.6). In $\mathrm{KNO}_{3}$ solutions the concentration of $\mathrm{H}_{2} \mathrm{O}_{2}$ is undetectable within the limits of detection of the $\mathrm{UV}$-Vis experiment. In contrast, in $\mathrm{KCl}, \mathrm{H}_{2} \mathrm{O}_{2}$ is clearly present over the entire time span of the experiment.

Interestingly, whilst the EPR data shows a two times increase in the amount of DMPO-OH in $\mathrm{KCl}$ compared to $\mathrm{KNO}_{3}$, the $\mathrm{sp}^{2}$ carbon bulk etch rate data (Figure 4) shows a greater than one order of magnitude increase in the etch rate in $\mathrm{KCl}$ compared to $\mathrm{KNO}_{3}$. As well as radical species the production of non-radical oxidising species is also possible. For example, EC oxidation of the chloride ions can result in chlorine radical production, which can quickly produce chlorine gas, hypochlorous acid or hypochlorite, dependent on solution $\mathrm{pH}$. Based on the $\mathrm{H}_{2} \mathrm{O}_{2}$ chemical etch data in Section 3.2, and the fact these species have lower thermodynamic oxidising potentials than $\mathrm{H}_{2} \mathrm{O}_{2}$, production of such species alone is unlikely to be sufficient to result in the observed etch rates. However, their subsequent chemical reactions are also possible routes for generation of $\mathrm{HO}_{(\mathrm{aq})}$ and also singlet oxygen; some of the many possible reaction pathways are detailed in SI.7 and Equations S7-S9.

The EPR spectra after electrolysis of $\mathrm{K}_{2} \mathrm{SO}_{4}$ has the highest concentration of DMPO-OH for all three electrolytes, with the double integrated intensity being nine times larger than that in the $\mathrm{KNO}_{3}$ solution. Sulfate radicals $\left(\mathrm{SO}_{4}{ }^{-}\right)$, with a lifetime of $\mu \mathrm{s}$, are highly oxidising $\left(E^{0}=\right.$ $2.44 \mathrm{~V} v s \mathrm{RHE})^{31}$ and can be generated oxidatively on Pt electrodes in sulfate containing media, ${ }^{49,50}$ Equation 9. In the EPR spectrum, the splitting pattern of $\mathrm{DMPO}^{-\mathrm{SO}_{4}}$ is obscured by that of DMPO-OH when both are present in the system, and over time DMPO-SO 4 will decompose to DMPO-OH. ${ }^{51}$

$$
\text { Equation 9: } \quad \mathrm{SO}_{4}{ }^{2-}{ }_{(a q)} \rightarrow \mathrm{SO}_{4}{ }^{-{ }_{(a q)}}+e^{-} \quad\left(E^{0}=2.44 \mathrm{~V} v s \mathrm{RHE}\right)^{50}
$$


The highly reactive $\mathrm{SO}_{4}{ }^{--}$radicals are also able to abstract a proton from water and produce HO (Equation 10). ${ }^{49}$ Given the high concentrations of sulfate ions and water molecules in the high conductivity solution, Equation 10 is thought to be a preferred route for $\mathrm{HO}^{\bullet}$ generation, resulting in high initial concentrations of $\mathrm{HO}^{\circ}$.

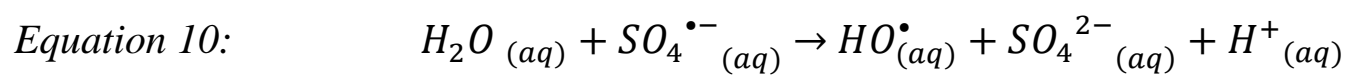

Once $\mathrm{SO}_{4}{ }^{--}$and $\mathrm{HO}^{\circ}$ radicals have been produced there are a host of reaction pathways that can occur (see Equations S10 to S15 in SI.7). ${ }^{38,52}$ These reaction pathways are referred to as chaining mechanisms and will result in the regeneration of the radicals and generation of more stable oxidising species. This, we believe, is the reason for the appearance of the $\mathrm{HO}^{\bullet}$ radicals at timescales much longer than their lifetime and their detection in the system once the electrode potential has been switched off. This behaviour is thought to be the dominant factor behind the significant DMPO-OH signal in sulfate media. Increased $\mathrm{HO}^{\bullet}$ levels should also result in an increased prominence of Equation 7 and Equation 8, compared to $\mathrm{KNO}_{3}$ solutions. $\mathrm{H}_{2} \mathrm{O}_{2}$ presence in sulfate solutions is also verified by the UV-Vis spectra in SI.6. As with $\mathrm{KCl}$, the generation of non-radical species such as $\mathrm{S}_{2} \mathrm{O}_{8}{ }^{2-}\left(\mathrm{E}^{0}=2.01 \mathrm{~V}\right.$ vs $\left.\mathrm{RHE}\right)$, and their subsequent reactions with radicals could also be contributing to etching ${ }^{53}$.

To identify any gaseous products produced from the etching process, headspace on-line electrochemical mass spectrometry (HS-OLEMS) was employed; described in detail in SI.8. In order to measure sufficient gaseous product, it was necessary to replace the implanted $\mathrm{sp}^{2}$ carbon - diamond substrate with a large piece of graphite (diameter $=5 \mathrm{~mm}$, length $=10 \mathrm{~mm}$ ). These experiments revealed that at all potentials trialled (5-30 V) the major carbon-containing gaseous product was $\mathrm{CO}_{2}$. The amount of $\mathrm{CO}_{2}$ produced increased with increasing potential. The presence of $\mathrm{CO}_{2}$ provides evidence for the majority of etching occurring due to oxidation of the $\mathrm{sp}^{2}$ carbon layer.

\subsection{The Effect of Concentration and $\mathrm{pH}$ in Sulfate Media}

As sulfate containing electrolytes gave rise to the highest bulk etch rates, this electrolyte was chosen for further study. The chaining reactions which are most critical for etching of the $\mathrm{sp}^{2}$ carbon layer are those which increase the number of radicals at the surface of the $\mathrm{sp}^{2}$ carbon layer. Once a sulfate radical, $\mathrm{SO}_{4}^{-*}$, is generated on the Pt electrodes it can react with any solution component. Reaction with water results in the generation of $\mathrm{HO}^{\bullet}$ as per Equation 10. However, if this happens too far away from the $\mathrm{sp}^{2}$ carbon edge the radical cannot contribute to etching as it will not react with the $\mathrm{sp}^{2}$ carbon during its very short lifetime. In contrast, if 
$\mathrm{HO}^{\bullet}$ encounters a $\mathrm{SO}_{4}{ }^{2-}$ within its lifetime the reverse of Equation 10 is also possible, regenerating the $\mathrm{SO}_{4}{ }^{-\bullet}$. This chaining can continue until either the $\mathrm{SO}_{4}{ }^{-\bullet}$ or $\mathrm{HO}^{*}$ radical reaches the edge of the $\mathrm{sp}^{2}$ carbon layer and etching can take place.

To test this theory, the effect of sulfate concentration was investigated for concentrations over the range $30-250 \mathrm{mM} \mathrm{K}_{2} \mathrm{SO}_{4}$. Data for $250 \mathrm{mM} \mathrm{KNO}_{3}$ was also included for comparison and is the data point at $0 \mathrm{mM}$ sulfate, shown in Figure $6 \mathbf{a}$.
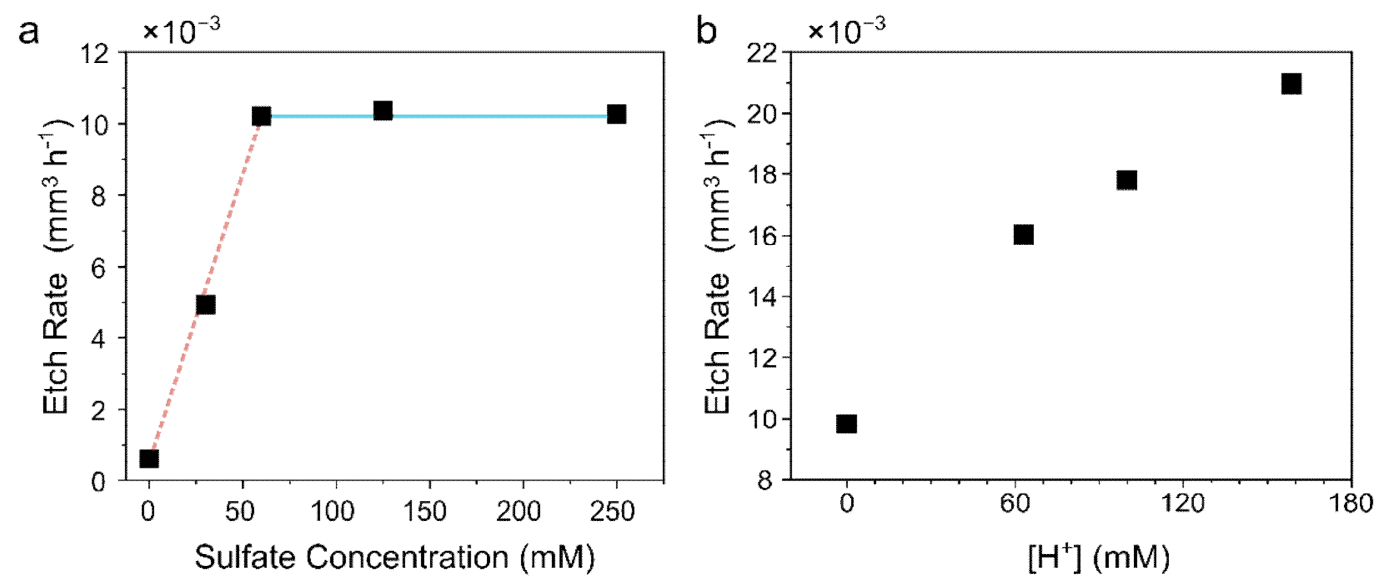

Figure 6: (a) Bulk etch rates for a $3.5 \mathrm{~mm} \times 3.5 \mathrm{~mm} \mathrm{CVD} \mathrm{single} \mathrm{crystal} \mathrm{diamond} \mathrm{in} \mathrm{aerated} \mathrm{KNO}_{3}$ solution at 0 $\mathrm{mM}$ sulfate and $30-250 \mathrm{mM}$ solutions of $\mathrm{K}_{2} \mathrm{SO}_{4}$. Lines added as guides to the eye and do not represent fits. (b) Etch rates for a $4.1 \mathrm{~mm} \times 4.1 \mathrm{~mm}$ square CVD single crystal diamond in aerated solutions with constant sulfate (250 mM) comprised of $\mathrm{K}_{2} \mathrm{SO}_{4}$ and $\mathrm{H}_{2} \mathrm{SO}_{4}$, but with $\mathrm{pH}$ varying between $0.8-7.1$. The solution was held at 25 ${ }^{\circ} \mathrm{C}$.

At sulfate concentrations in the range $0-60 \mathrm{mM}$, the etch rate increases linearly (dashed, pink line) with increasing sulfate concentration. This is likely a result of the increased sulfate ion concentration which increases the chances of a $\mathrm{HO}^{\bullet}$ encountering $\mathrm{SO}_{4}{ }^{2-}$ within the distance it can travel during its lifetime. This results in an increased number of chaining events and ultimately results in a higher number of radicals available at the $\mathrm{sp}^{2}$ carbon solution interface to etch the $\mathrm{sp}^{2}$ carbon material. As the concentration of $\mathrm{SO}_{4}{ }^{2-}$ increases, the $\mathrm{SO}_{4}{ }^{2-}-\mathrm{SO}_{4}{ }^{2-}$ inter-ion spacing decreases. While the spacing has not decreased to a point where a $\mathrm{HO}^{\bullet}$ is guaranteed to encounter a $\mathrm{SO}_{4}{ }^{2-}$ in its short lifetime, at $60 \mathrm{mM}$ a plateau is still observed (blue line, Figure 6a). A likely explanation for this is that as the radical concentration increases, the chances of radical recombination also increase, as shown in SI.7 Equation S4, S6 and S12. Hence further increases in $\mathrm{SO}_{4}{ }^{2-}$ concentration won't necessarily increase the number of radicals available at the edge of the $\mathrm{sp}^{2}$ carbon layer. Note, as the concentration of $\mathrm{K}_{2} \mathrm{SO}_{4}$ 
increases, the conductivity also increases from $7-42 \mathrm{mS} \mathrm{cm}{ }^{-1}$ across the range, however the plateau region from $60 \mathrm{mM}-250 \mathrm{mM} \mathrm{K}_{2} \mathrm{SO}_{4}$ shows no noticeable change in etch rate. This suggests that conductivity has little effect on bulk etch rate in this region.

As the generation of $\mathrm{HO}^{\bullet}$ via $\mathrm{SO}_{4}{ }^{-}$- shows a $\mathrm{pH}$ dependence (Equation 10), ${ }^{52}$ the effect of $\mathrm{pH}$ on etch rate was investigated. Mixtures of $\mathrm{K}_{2} \mathrm{SO}_{4}$ and $\mathrm{H}_{2} \mathrm{SO}_{4}$ were used to vary solution $\mathrm{pH}$ over the $\mathrm{pH}$ range $0.8-7.1$ whilst maintaining the total sulfate concentration at $250 \mathrm{mM}$ (Figure 6b). A decrease in $\mathrm{pH}$ has the effect of increasing the bulk etch rate and a maximum bulk etch rate of $21 \mathrm{~mm}^{3} \mathrm{hr}^{-1}$ is achieved at $\mathrm{pH}$ 0.8. As shown vide supra (Figure 6a), increasing conductivity again has little effect on the etch rate. The increase in etch rate can therefore be attributed to the increase in proton concentration.

\subsection{The Effect of Temperature in Sulfate Media}

To investigate if further improvements to etch rate could be made by varying the temperature, etches were performed in a solution of $50 \mathrm{mM} \mathrm{H}_{2} \mathrm{SO}_{4}$ at temperatures from $10{ }^{\circ} \mathrm{C}-70{ }^{\circ} \mathrm{C}$ (Figure 7).
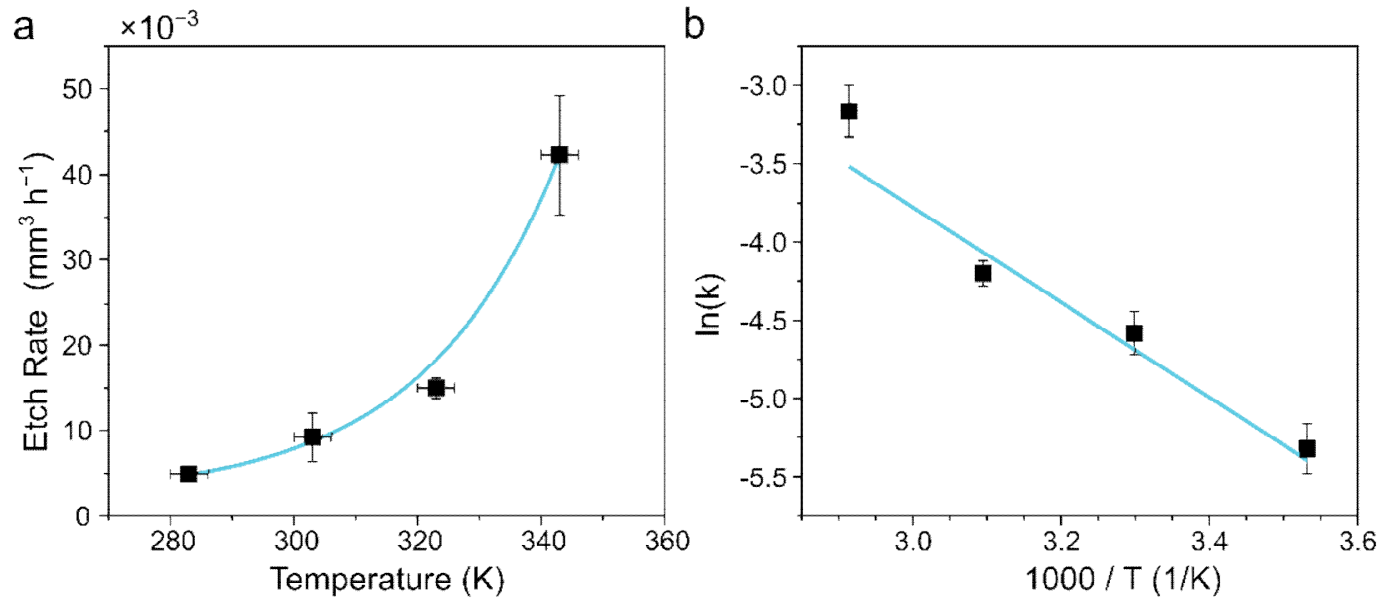

Figure 7: a) Rate vs temperature plot for a $3.5 \mathrm{~mm} \times 3.5 \mathrm{~mm}$ square HPHT single crystal diamond from $10-$ $70{ }^{\circ} \mathrm{C}$ in $50 \mathrm{mM}$ aerated $\mathrm{H}_{2} \mathrm{SO}_{4}, 30 \mathrm{~V}$ was applied between two platinum electrodes until etching was complete. b) Arrhenius plot of etch rate versus $1000 / \mathrm{T}$ for a in $50 \mathrm{mM} \mathrm{H}_{2} \mathrm{SO}_{4}$. Data in this figure was completed as $\mathrm{n}=3$.

The etch rate shows an exponential increase with temperature. An Arrhenius plot of the data gives an activation energy of $377 \pm 80 \mathrm{~kJ} \mathrm{~mol}^{-1}$. This is a realistic value considering the removal of $\mathrm{sp}^{2}$ bonded carbon will involve the breaking of C-C bond with a typical enthalpies in the range of $67-960 \mathrm{~kJ} \mathrm{~mol}^{-1} .{ }^{54}$ The highest rate was observed at $70{ }^{\circ} \mathrm{C}$, the highest temperature trialled, which gave a bulk rate of $42 \times 10^{-3} \mathrm{~mm}^{3} \mathrm{~h}^{-1}$, over $\times 40$ faster than previously reported etch rates in the literature. ${ }^{4,10,12}$ These data indicate the advantages of etching in solutions at elevated temperatures. Although the flow set-up utilised herein allowed for temperature 
control, for practical applications, an elevated temperature could be obtained simply by using smaller volume $(100 \mathrm{~mL})$ static cells which are heated as a result of joule heating, due to the large, applied potentials. Note, for the data in Figure 7, sufficient samples were available to obtain $\mathrm{n}=3$, and the errors obtained are a good indication of error in the measurement of etch rate using the technique outlined herein, for all experiments.

Overall, the data indicates that the most efficient etch solution is one which contains sulfate at a concentration of at least $60 \mathrm{mM}$ in acidic media $(\mathrm{pH}>1)$ at $70^{\circ} \mathrm{C}$. A graphical comparison of all the etch conditions trialled in this article can be found in SI.9 This electrolyte also has the added practical advantages that in its pure form it is a liquid and therefore should solution evaporation occur the electrolyte will not leave salt residues. This also avoids further cleaning steps to remove salt deposits from the membranes. A practical list of recommendations for replicating the most favourable etch process, as well as designs for 3D printed etch cells are provided in SI.10 and SI.11.

\section{Conclusions}

The impact of electrochemical initiation of radical generating chemical pathways in solution, on increasing the bulk etch rate of implanted thin $\mathrm{sp}^{2}$ carbon layers in single crystal diamond, has been demonstrated. A novel optical etch tracking method was used to monitor etching, via quantification of the colour change associated with removal of the black $\mathrm{sp}^{2}$ carbon layer in the translucent diamond. Electrolyte chemical identity and concentration was found to play a crucial role, with conductive sulfate and chloride solutions showing significantly increased bulk etch rates (an order of magnitude) compared to conductive nitrate solutions and low conductivity boric acid solutions. The most dramatic improvement, $42 \mathrm{~mm}^{3} \mathrm{hr}^{-1}$ was achieved using sulfate electrolyte in acidic media at elevated temperature. This represents a $\times 40$ increase compared to the current methods which also employ a non-contact electrochemical set-ups but with low conductivity solutions (bipolar arrangement).

Complementary EPR experiments showed the chloride and sulfate electrolytes also produced sizeable quantities of $\mathrm{HO}^{\bullet}(\mathrm{DMPO}-\mathrm{OH})$. Boric acid showed no radicals whilst nitrate showed a minimal amount. As the DMPO spin trap was added ca. $30 \mathrm{~s}$ after the potential had been switched off, any $\mathrm{HO}^{\circ}$ (lifetime $\leq \mu \mathrm{s}$ ) produced via electrochemical means should no longer be present. The detection of $\mathrm{HO}^{\bullet}$ demonstrated the existence of electrochemically initiated, solution chemistry radical generation pathways which enabled $\mathrm{HO}^{\bullet}$ to be observed on timescales much longer $\left(>10^{7}\right)$ than their lifetime. The chloride and sulfate anions (and their 
electrochemically oxidised forms) also contributed to the production of other species e.g. $\mathrm{H}_{2} \mathrm{O}_{2}$, which also aided radical production.

The significant reduction in time during the bulk etch region of the process improves the viability of the implantation and non-contact electrochemical etch as a process to produce thin diamond membranes. However, there is still scope for advancement. Further work on how the material properties of the $\mathrm{sp}^{2}$ carbon implanted diamond or single crystal diamond itself, influence the etch rate, is required, with the aim of shortening both the induction and limiting bulk etch rate times. Finally, we believe there are wider benefits to be gained in diamond nanofabrication by using this combined implantation, non-contact electrochemical etching approach, for example in the nanofabrication of diamond pillars, channels or pores.

\section{Declaration of Competing Interests}

The authors declare that they have no known competing financial interests or personal relationships that could have appeared to influence the work reported in this paper.

\section{CRediT Authorship Contribution Statement}

Joshua J. Tully performed, conceptualisation, methodology, formal analysis, investigation, writing-original draft, writing - review and editing, and visualisation. Emily Braxton performed, methodology, formal analysis, investigation, writing-original draft, writing-review and editing, and visualisation. Samuel J. Cobb performed, conceptualisation, methodology, investigation, writing-review and editing, and visualisation. Ben G. Breeze performed, methodology, formal analysis, investigation, and writing - review and editing. Matthew Markham supplied conceptualisation and resources. Mark E. Newton provided supervision. Paramaconi Rodriguez performed, methodology, formal analysis, investigation, writingreview and editing, and visualisation. Julie V. Macpherson supplied conceptualisation, writing - review and editing, supervision, project administration, and funding acquisition.

\section{Acknowledgements}

The authors acknowledge use of Spectroscopy Research Technology Platform facilities at the University of Warwick. Implantation was performed under EPSRC grant EP/M013243/1. MEN acknowledges funding from EPSRC grant EP/M013243/1. JT acknowledges The Royal Society for financial support under the Industry Fellows $\mathrm{PhD}$ studentship scheme (INF/PHD/180016). EB thanks EPSRC for a PhD studentship through the EPSRC Centre for Doctoral Training in Molecular Analytical Science (EP/L015307/1). SJC thanks the Centre for 
Doctorial Training in Diamond Science and Technology (EP/L015315/1) and the Defence Science and Technology Laboratory (Dstl). Dr. David Perry, Dr. Gabriel Meloni, and Dr. James Teahan (Warwick Chemistry) are acknowledged for their assistance in writing the MATLAB code used. Dr. James Teahan is also acknowledged for his insights into bipolar electrochemistry. Rachel Lai-Cheong is acknowledged for researching hydrogen peroxide detection methods by UV-Vis. Element 6 Ltd is acknowledged for supplying all the single crystal diamond substrates.

\section{Appendix A. Supplementary Data}

Supplementary data related to this article, including the STL files for the 3D printed cells, can be found at:

\section{References}

(1) Balmer, R. S.; Brandon, J. R.; Clewes, S. L.; Dhillon, H. K.; Dodson, J. M.; Friel, I. Chemical Vapour Deposition Synthetic Diamond: Materials, Technology and Applications. J. Phys. Condens. Matter 2009, $21 \quad$ (36), 364221. https://doi.org/10.1088/0953-8984/21/36/364221.

(2) Doherty, M. W.; Manson, N. B.; Delaney, P.; Jelezko, F.; Wrachtrup, J.; Hollenberg, L. C. L. The Nitrogen-Vacancy Colour Centre in Diamond. Phys. Rep. 2013, 528 (1), 145. https://doi.org/10.1016/j.physrep.2013.02.001.

(3) Jelezko, F.; Wrachtrup, J. Single Defect Centres in Diamond: A Review. Phys. Status Solidi Appl. Mater. Sci. 2006, $203 \quad$ (13), 3207-3225. https://doi.org/10.1002/pssa.200671403.

(4) Piracha, A. H.; Ganesan, K.; Lau, D. W. M.; Stacey, A.; McGuinness, L. P.; Tomljenovic-Hanic, S.; Prawer, S. Scalable Fabrication of High-Quality, Ultra-Thin Single Crystal Diamond Membrane Windows. Nanoscale 2016, 8 (12), 6860-6865. https://doi.org/10.1039/C5NR08348F.

(5) Zaitsev, A. Optical Properties of Diamond; 2001; Vol. 134. https://doi.org/10.1007/9783-662-04548-0.

(6) Jelezko, F.; Wrachtrup, J. Single Defect Centres in Diamond: A Review. Phys. Status Solidi Appl. Mater. Sci. 2006, $203 \quad$ (13), 3207-3225. https://doi.org/10.1002/pssa.200671403. 
(7) Tatsumi, N.; Harano, K.; Ito, T.; Sumiya, H. Polishing Mechanism and Surface Damage Analysis of Type IIa Single Crystal Diamond Processed by Mechanical and Chemical Polishing Methods. Diam. Relat. Mater. 2016, 63, 80-85. https://doi.org/10.1016/j.diamond.2015.11.021.

(8) Hsieh, C.; Tsai, H.; Lai, H.; Hsieh, C.; Tsai, H.; Lai, H.; Lin, H. Comparison between Mechanical Method and Chemical-Assisted Mechanical Method for CVD Diamond Film Polishing. Proc. SPIE 2003, 4936 (1), 337. https://doi.org/doi:10.1117/12.469741.

(9) Schuelke, T.; Grotjohn, T. A. Diamond Polishing. Diam. Relat. Mater. 2013, 32, 17-26. https://doi.org/10.1016/j.diamond.2012.11.007.

(10) Marchywka, M.; Pehrsson, P. E.; Vestyck, D. J.; Moses, D. Low Energy Ion Implantation and Electrochemical Separation of Diamond Films. Appl. Phys. Lett. 1993, 63 (25), 3521-3523. https://doi.org/10.1063/1.110089.

(11) Pehrsson, P. E.; Mccormick, T.; Alexander, W. B.; Marchywka, M.; Black, D.; Butler, J. E.; Prawer, S. Homoepitaxial Mosaic Growth and Liftoff of Diamond Films. MRS Proc. 1995, 416, 51. https://doi.org/10.1557/PROC-416-51.

(12) Marchywka, M.; Pehrsson, P. E.; Binari, S. C.; Moses, D. Electrochemical Patterning of Amorphous Carbon on Diamond. J. Electrochem. Soc. 1993, 140 (2), L19-L22. https://doi.org/10.1149/1.2221093.

(13) Parikh, N. R.; Hunn, J. D.; McGucken, E.; Swanson, M. L.; White, C. W.; Rudder, R. A.; Malta, D. P.; Posthill, J. B.; Markunas, R. J. Single-Crystal Diamond Plate Liftoff Achieved by Ion Implantation and Subsequent Annealing. Appl. Phys. Lett. 1992, 61 (26), 3124-3126. https://doi.org/10.1063/1.107981.

(14) Abbott, A. P.; Capper, G.; McKenzie, K. J.; Glidle, A.; Ryder, K. S. Electropolishing of Stainless Steels in a Choline Chloride Based Ionic Liquid: An Electrochemical Study with Surface Characterisation Using SEM and Atomic Force Microscopy. Phys. Chem. Chem. Phys. 2006, 8 (36), 4214-4221. https://doi.org/10.1039/b607763n.

(15) Karim, W. O.; Abbott, A. P.; Cihangir, S.; Ryder, K. S. Electropolishing of Nickel and Cobalt in Deep Eutectic Solvents. Trans. Inst. Met. Finish. 2018, 96 (4), 200-205. https://doi.org/10.1080/00202967.2018.1470400.

(16) Crooks, R. M. Principles of Bipolar Electrochemistry. ChemElectroChem 2016, 3 (3), 
357-359. https://doi.org/10.1002/celc.201500549.

(17) Mavré, F.; Anand, R. K.; Laws, D. R.; Chow, K. F.; Chang, B. Y.; Crooks, J. A.; Crooks, R. M. Bipolar Electrodes: A Useful Tool for Concentration, Separation, and Detection of Analytes in Microelectrochemical Systems. Anal. Chem. 2010, 82 (21), 8766-8774. https://doi.org/10.1021/ac101262v.

(18) Posthill, J. B.; Malta, D. P.; Humphreys, T. P.; Hudson, G. C.; Thomas, R. E.; Rudder, R. A.; Markunas, R. J. Fabrication of a Free-Standing, Synthetic, Single Crystal Diamond Plate Using Ion Implantation and Plasma-Enhanced Chemical Vapor Deposition. In Film Synthesis and Growth Using Energetic Beams; 1995; Vol. 388, pp 299-304.

(19) Mokuno, Y.; Chayahara, A.; Yamada, H. Synthesis of Large Single Crystal Diamond Plates by High Rate Homoepitaxial Growth Using Microwave Plasma CVD and Liftoff Process. Diam. Relat. Mater. 2008, $17 \quad$ (4-5), 415-418. https://doi.org/10.1016/j.diamond.2007.12.058.

(20) Wang, C. F.; Hu, E. L.; Yang, J.; Butler, J. E. Fabrication of Suspended Single Crystal Diamond Devices by Electrochemical Etch. J. Vac. Sci. Technol. B Microelectron. Nanom. Struct. 2007, 25 (3), 730. https://doi.org/10.1116/1.2731327.

(21) Yang, J.; Wang, C. F.; Hu, E. L.; Butler, J. E. Lift -Off Process to Get Free-Standing High Quality Single Crystal Diamond Films and Suspended Single Crystal Diamond Devices. In Materials Research Society Symposim Proceedings; 2007; Vol. 956.

(22) Ayres, Z. J.; Borrill, A. J.; Newland, J. C.; Newton, M. E.; Macpherson, J. V. Controlled $\mathrm{sp}^{2}$ Functionalization of Boron Doped Diamond as a Route for the Fabrication of Robust and Nernstian pH Electrodes. Anal. Chem. 2016, 88 (1), 974-980. https://doi.org/10.1021/acs.analchem.5b03732.

(23) Ziegler, J. F.; Ziegler, M. D.; Biersack, J. P. SRIM - The Stopping and Range of Ions in Matter (2010). Nucl. Instruments Methods Phys. Res. Sect. B Beam Interact. with Mater. Atoms 2010, 268 (11-12), 1818-1823. https://doi.org/10.1016/j.nimb.2010.02.091.

(24) Uzan-Saguy, C.; Cytermann, C.; Brener, R.; Richter, V.; Shaanan, M.; Kalish, R. Damage Threshold for Ion-Beam Induced Graphitization of Diamond. Appl. Phys. Lett. 1995, 67 (9), 1194. https://doi.org/10.1063/1.115004. 
(25) Stoll, S.; Schweiger, A. EasySpin, a Comprehensive Software Package for Spectral Simulation and Analysis in EPR. J. Magn. Reson. 2006, 178 (1), 42-55. https://doi.org/10.1016/j.jmr.2005.08.013.

(26) Kabay, N.; Bryjak, M. Boron Removal From Seawater Using Reverse Osmosis Integrated Processes; Elsevier B.V., 2015. https://doi.org/10.1016/B978-0-444-634542.00009-5.

(27) Pauleau, Y.; Barna, P. B. Protective Coatings and Thin Films: Synthesis, Characterization, and Applications; Springer, 1997.

(28) Shimada, T.; Kubota, S.; Yanase, T.; Nagahama, T. Formation of Graphite Zigzag Edges by Cathodic Electrochemical Etching in Acidic Solution. Carbon N. Y. 2014, 67, 300303. https://doi.org/10.1016/j.carbon.2013.09.092.

(29) Liu, H.; Xu, Q.; Yan, C. On-Line Mass Spectrometry Study of Electrochemical Corrosion of the Graphite Electrode for Vanadium Redox Flow Battery. Electrochem. commun. 2013, 28, 58-62. https://doi.org/10.1016/j.elecom.2012.12.011.

(30) Pourbaix, M.; Zhang, H.; Pourbaix, A. Presentation of an Atlas of Chemical and Electrochemical Equilibria in the Presence of a Gaseous Phase. Mater. Sci. Forum 1997, 251-254, 143-148. https://doi.org/10.4028/www.scientific.net/msf.251-254.143.

(31) Armstrong, D. A.; Huie, R. E.; Koppenol, W. H.; Lymar, S. V.; Merenyi, G.; Neta, P.; Ruscic, B. Standard Electrode Potentials Involving Radicals in Aqueous Solution: Inorganic Radicals (IUPAC Technical Report). IUPAC Tech. Rep. 2002, PAC-REP-14. https://doi.org/10.1515/ci-2016-0217.

(32) Vatistas, N. Electrocatalytic Properties of BDD Anodes: Its Loosely Adsorbed Hydroxyl Radicals. Int. J. Electrochem. 2012, 2012, 1-7. https://doi.org/10.1155/2012/507516.

(33) Morcos, I.; Yeager, E. Kinetic Studies of the Oxygen-Peroxide Couple on Pyrolytic Graphite. Electrochim. Acta 1970, 15 (6), 953-975. https://doi.org/10.1016/00134686(70)80037-8.

(34) Bard, A. J.; Faulkner, L. R. Electrochemical Methods - Fundamentals and Applications, 2nd ed.; Wiley, 2001; Vol. 2.

(35) Buettner, G. R. Spin Trapping - Electron-Spin-Resonance Parameters of Spin Adducts. Free Radic. Bio. Med. 1987, 3 (4), 259-303. https://doi.org/10.1016/s0891- 
5849(87)80033-3.

(36) Weil, J. A. A Review of Electron Spin Spectroscopy and Its Application to the Study of Paramagnetic Defects in Crystalline Quartz. Phys. Chem. Miner. 1984, 10 (4), 149-165. https://doi.org/10.1007/BF00311472.

(37) Simond, O.; Schaller, V.; Comninellis, C. Theoretical Model for the Anodic Oxidation of Organics on Metal Oxide Electrodes. Electrochim. Acta 1997, 42 (13-14), 20092012. https://doi.org/10.1016/S0013-4686(97)85475-8.

(38) Méndez-cute;az, J.; Sánchez-Polo, M.; Rivera-Utrilla, J.; Canonica, S.; von Gunten, U. Advanced Oxidation of the Surfactant SDBS by Means of Hydroxyl and Sulphate Radicals. Chem. Eng. J. 2010, $163 \quad$ (3), 300-306. https://doi.org/10.1016/j.cej.2010.08.002.

(39) Weiss, J. The Free Radical Mechanism in the Reactions of Hydrogen Peroxide. Adv. Catal. 1952, 4, 343-365. https://doi.org/10.1016/S0360-0564(08)60618-5.

(40) Stephens, I. E. L.; Bondarenko, A. S.; Grønbjerg, U.; Rossmeisl, J.; Chorkendorff, I. Understanding the Electrocatalysis of Oxygen Reduction on Platinum and Its Alloys. Energy Environ. Sci. 2012, 5 (5), 6744-6762. https://doi.org/10.1039/c2ee03590a.

(41) Mokudai, T.; Nakamura, K.; Kanno, T.; Niwano, Y. Presence of Hydrogen Peroxide, a Source of Hydroxyl Radicals, in Acid Electrolyzed Water. PLoS One 2012, 7 (9), e46392. https://doi.org/10.1371/journal.pone.0046392.

(42) Gómez-Marín, A.; Feliu, J.; Edson, T. Reaction Mechanism for Oxygen Reduction on Platinum: Existence of a Fast Initial Chemical Step and a Soluble Species Different from $\mathrm{H}_{2} \mathrm{O}_{2}$. ACS Catal. 2018, 8 (9), 7931-7943. https://doi.org/10.1021/acscatal.8b01291.

(43) Schmidt, T. J.; Paulus, U. A.; Gasteiger, H. A.; Behm, R. J. The Oxygen Reduction Reaction on a Pt/Carbon Fuel Cell Catalyst in the Presence of Chloride Anions. $J$. Electroanal. Chem. 2001, 508 (1-2), 41-47. https://doi.org/10.1016/S00220728(01)00499-5.

(44) Kwon, B. G.; Kim, J.-O.; Kwon, J.-K. An Advanced Kinetic Method for $\mathrm{HO}_{2}{ }^{\prime} / \mathrm{O}_{2}{ }^{-*}$ Determination by Using Terephthalate in the Aqueous Solution. Environ. Eng. Res. 2012, 17 (4), 205-210. https://doi.org/10.4491/eer.2012.17.4.205.

(45) Finkelstein, E.; Rosen, G. M.; Rauckman, E. J.; Paxton, J. Spin Trapping of Superoxide. 
Mol. Pharmacol. 1979, 16 (2), 676-685.

(46) Finkelstein, E.; Rosen, G. M.; Rauckman, E. J. Spin Trapping of Superoxide and Hydroxyl Radical: Practical Aspects. Arch. Biochem. Biophys. 1980, 200 (1), 1-16. https://doi.org/10.1016/0003-9861(80)90323-9.

(47) Buettner, G. R.; Oberley, L. W. Considerations in the Spin Trapping of Superoxide and Hydroxyl Radical in Aqueous Systems Using 5,5-Dimethyl-1-Pyrroline-1-Oxide. Biochem. Biophys. Res. Commun. 1978, 83 (1), 69-74. https://doi.org/10.1016/0006291X(78)90398-4.

(48) Shoji, T.; Li, L.; Abe, Y.; Ogata, M.; Ishimoto, Y.; Gonda, R.; Mashino, T.; Mochizuki, M.; Uemoto, M.; Miyata, N. DMPO-OH Radical Formation from 5,5-Dimethyl-1Pyrroline N -Oxide (DMPO) in Hot Water. Anal. Sci. 2007, 23 (February), 219-221.

(49) Reshetnyak, O. V.; Koval'chuk, E. P. A Possible Scheme of Electrochemiluminescence Generation on Platinum Cathodes in Aqueous Solutions of Peroxydisulfates. Electrochim. Acta 1998, 43 (5-6), 465-469. https://doi.org/10.1016/S00134686(97)00138-2.

(50) Bolleta, F.; Ciano, M.; Balzani, V.; Serpone, N. Polypyridine Transition Metal Complexes as Light Emission Sensitizers in the Electrochemical Reduction of the Persulfate Ion. Inorganica Chim. Acta 1982, 62 (C), 207-213. https://doi.org/10.1016/S0020-1693(00)88503-5.

(51) Zamora, P. L.; Villamena, F. A. Theoretical and Experimental Studies of the Spin Trapping of Inorganic Radicals by 5,5-Dimethyl-1-Pyrroline N-Oxide (DMPO). 3. Sulfur Dioxide, Sulfite, and Sulfate Radical Anions. J. Phys. Chem. A 2012, 116 (26), 7210-7218. https://doi.org/10.1021/jp3039169.

(52) Liang, C.; Su, H.W. Identification of Sulfate and Hydroxyl Radicals in Thermally Activated Persulfate. Ind. Eng. Chem. Res. 2009, 48 (11), 5558-5562. https://doi.org/10.1021/ie9002848.

(53) Irkham; Watanabe, T.; Fiorani, A.; Valenti, G.; Paolucci, F.; Einaga, Y. Co-Reactanton-Demand ECL: Electrogenerated Chemiluminescence by the in Situ Production of $\mathrm{S}$ ${ }_{2} \mathrm{O}_{8}{ }^{2-}$ at Boron-Doped Diamond Electrodes. J. Am. Chem. Soc. 2016, 138 (48), 1563615641. https://doi.org/10.1021/jacs.6b09020. 
(54) Zavitsas, A. A. The Relation between Bond Lengths and Dissociation Energies of Carbon-Carbon Bonds. J. Phys. Chem. A 2003, 107 (6), 897-898. https://doi.org/10.1021/jp0269367. 